\title{
Acute Liver Injury That Followed Food-Dependent Exercise-Induced Anaphylaxis
}

\author{
Akihiro OKano, Kiyoshi Hajiro, Hiroshi TaKakuwa and Akiyoshi Nishio
}

\begin{abstract}
We describe an unusual case of acute liver injury that followed food-dependent exerciseinduced anaphylaxis (FDEIAn). A 45-year-old man who experienced anaphylactic shock induced by postprandial exercise and took alcohol that night was admitted the following day to our hospital because of general fatigue. Laboratory examinations revealed elevated hepatic enzymes (aspartate aminotransferase (AST) 6,110 IU, alanine aminotransferase (ALT) 4,178 IU). He had two similar episodes in the past. We speculated that acute liver injury in this case might be induced by interaction of anaphylactic shock and alcohol. (Internal Medicine 38: 650-654, 1999)
\end{abstract}

Key words: ischemic hepatitis, alcohol

\section{Introduction}

Food-dependent exercise-induced anaphylaxis (FDEIAn) is a distinct clinical entity, in which postprandial exercise induces anaphylactic shock. It is characterized by a unique syndrome consisting of generalized pruritus, urticaria, gastrointestinal symptoms, upper and lower respiratory obstruction, and vascular collapse (1-3). The coexistence of acute liver injury has not been documented. Here, we report a rare case of acute liver injury that followed FDEIAn.

\section{Case Report}

A 45-year-old man ate bread and drank milk at 2 PM on May 25, 1993, and played baseball one hour later. While playing, he became unconscious and generalized erythema developed. The unconsciousness lasted for twenty minutes and was resolved without any treatment, but erythema persisted. That night he drank about $2,000 \mathrm{ml}$ of beer (his usual amount was $350-700 \mathrm{ml} /$ day, three times/week). The following day, he was admitted to our hospital with general fatigue.

He had experienced two similar episodes in the past. The first episode (January 16, 1986) occurred when he started jogging one hour after eating biscuits. While jogging, urticaria and cold sweat developed and he collapsed. He recovered after one hour of rest and drank 2,000 $\mathrm{ml}$ of beer that night. Two days later he was admitted to our hospital because of general fatigue and elevated hepatic enzymes. The second episode (June 2,1992 ) occurred while he was playing baseball one hour after eating bread and drinking fruit juice. He noticed itching of eyes, nausea, and generalized erythema. That night he drank 2,500 $\mathrm{ml}$ of beer. The following day, he was admitted to our hospital because of general fatigue and liver dysfunction. He often had eaten bread and biscuits, but had not typically been doing exercise after food intake. There was no history of bronchial asthma, or drug or food allergy. He had not taken any medicine for several months. His family history was unremarkable.

On admission he was alert. His blood pressure was 110/70 $\mathrm{mmHg}$, pulse $80 / \mathrm{min}$ and temperature $36.5^{\circ} \mathrm{C}$. On physical examination generalized urticaria was noted (Fig. 1), and the conjunctivae bulbi were injected. There was neither hepatomegaly nor splenomegaly. Laboratory data on admission are shown in Table 1. Marked elevations of the lactate dehydrogenase (LDH), aspartate aminotransferase (AST), and alanine aminotransferase (ALT) were noted. Hepatitis virus markers were negative. Anti-nuclear antibody and anti-mitochondrial antibody were also negative.

Abdominal ultrasound demonstrated no abnormal findings. Liver biopsy was performed on the fifteenth hospital day when the AST and ALT values were $25 \mathrm{IU}$ and $81 \mathrm{IU}$, respectively. Liver biopsy specimen revealed non-specific changes. Microscopic examination showed no abnormal changes around the central vein; there was mild accumulation of lymphocytes in the portal area (Fig. 2).

Because of suspected allergic diseases, serum total immunoglobulin E (IgE) and specific IgE were tested on the fourth hospital day (Table 2). Total IgE was $407 \mathrm{U} / \mathrm{ml}$ (normal $\leqq 160$ $\mathrm{U} / \mathrm{ml}$ ). Specific IgE to candida and house dust were detected by radioallergosorbent test (RAST). Although specific IgE to wheat was not detected, the patient showed a positive skin re-

From the Department of Gastroenterology, Tenri Hospital, Tenri 


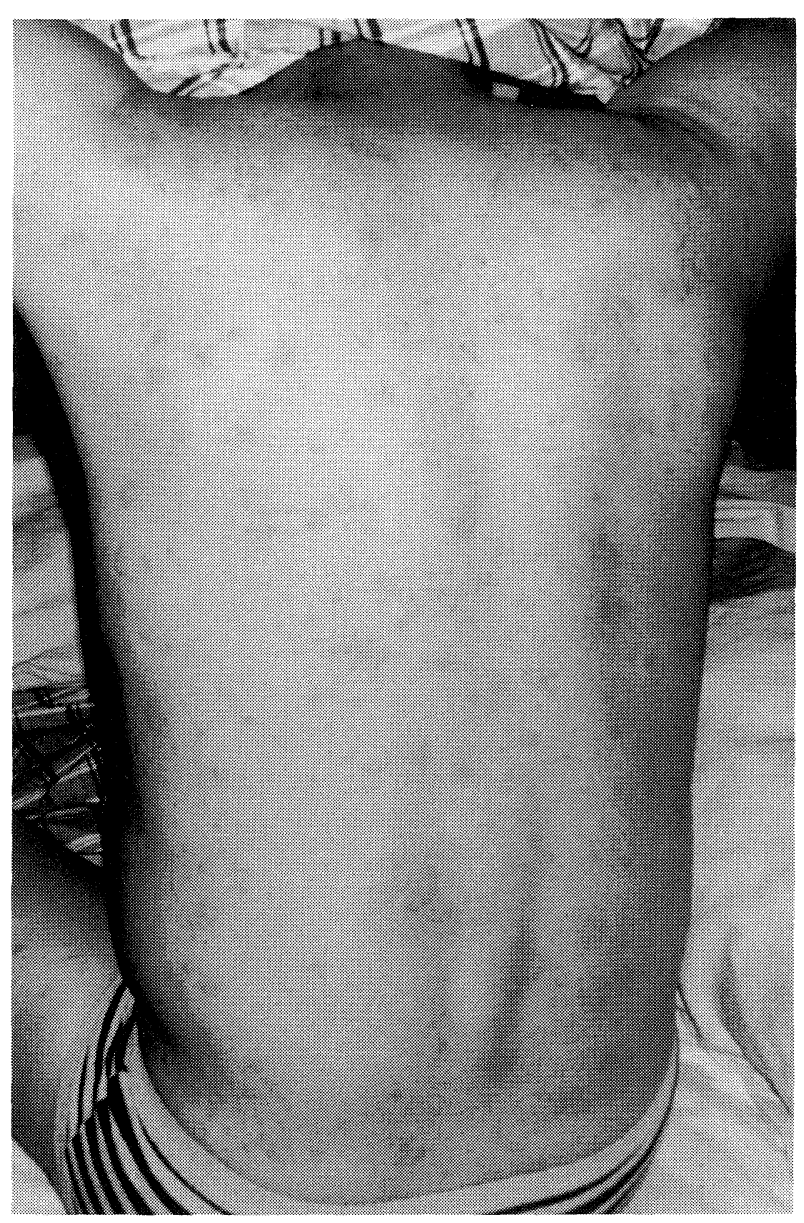

Figure 1. Urticaria on the trunk and extremities.

action to wheat. Exercise challenge tests after food intake were not performed. In each episode, he became asymptomatic and the laboratory data became normal without specific treatment (Fig. 3).

\section{Discussion}

Physical allergy is a group of diseases in which physical stimuli such as low temperature, heat, exercise, sun light and mechanical pressure can cause allergic symptoms. Exerciseinduced anaphylaxis (EIAn) in which symptoms are related to food intake is called FDEIAn. Many cases have been reported since Maulitz et al reported the first case in 1979 (4).

In EIAn, allergic symptoms are thought to be induced by chemical mediators that can be released from activated mast cells (5). Histamine is released from such cells following the binding of antigen by $\operatorname{IgE}$ antibody. Other vasoactive factors include prostaglandin $\mathrm{D} 2$, leukotrienes $\mathrm{C}$ and $\mathrm{D}$, platelet activating factor, bradykinin and tryptase $(6,7)$. Challenge tests induce elevated levels of histamine in patients with FDEIAn (3), suggesting the presence of histamine-mediated reactions as in EIAn. Attacks consist of allergic symptoms such as urti-

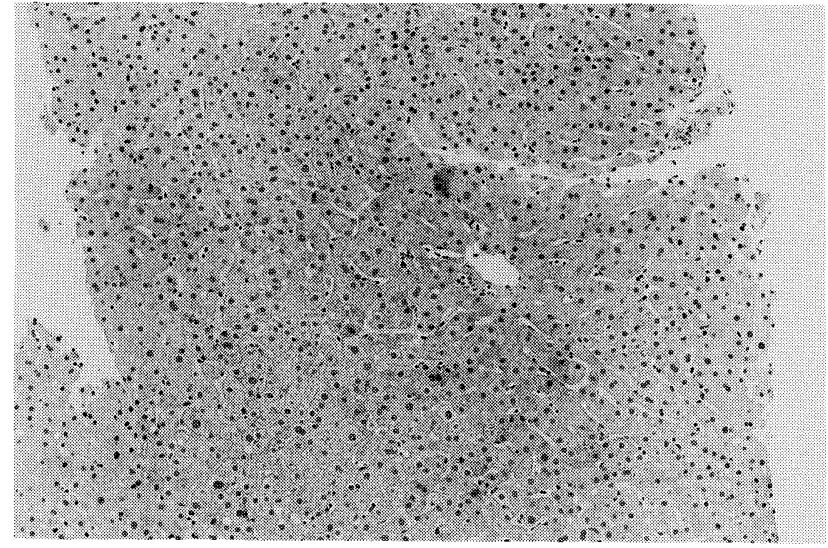

A

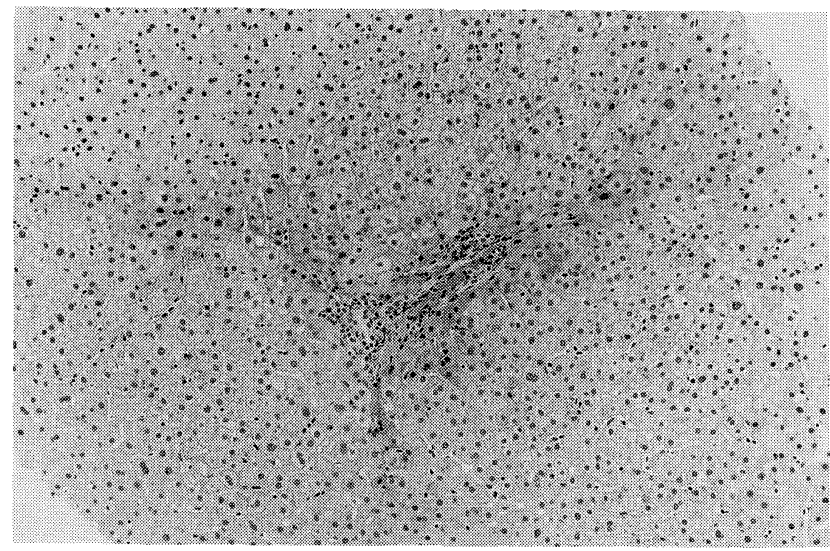

$\mathrm{B}$

Figure 2. The liver biopsy specimen after hepatic enzymes returned to almost normal. Microscopic examination showing no abnormal findings around the central vein (A), and mild accumulation of lymphocytes in the portal area (B) (HE stain, $\times 165)$.

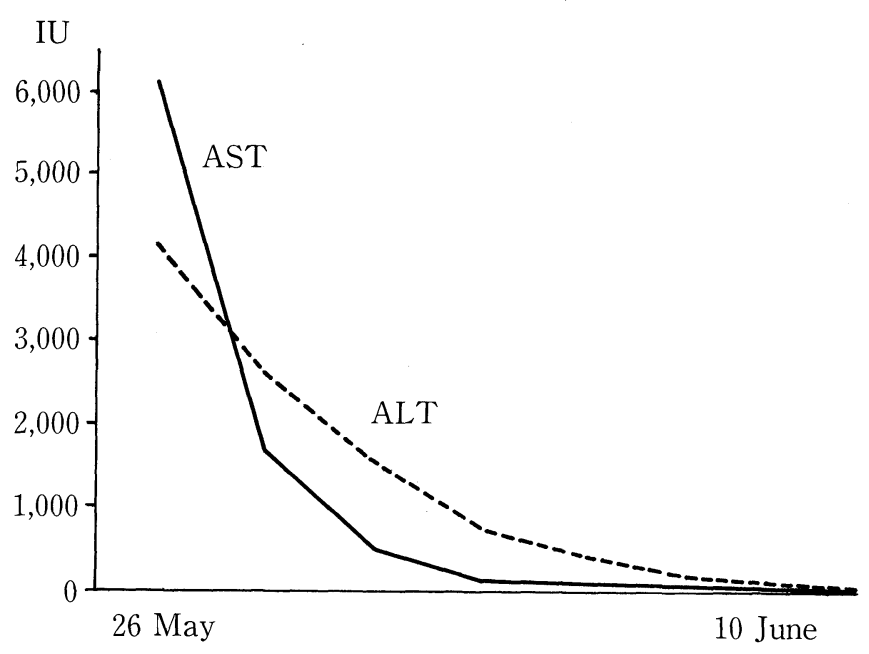

Figure 3. Changes in serum aminotransferase; AST and ALT values rapidly improved and normalized on the seventeenth hospital day. 
OKANO et al

Table 1. Laboratory Data on Admission

\begin{tabular}{|c|c|c|c|}
\hline & Jan. 18,1986 & June 3, 1992 & May 26, 1993 \\
\hline White blood cells $\left(/ \mathrm{mm}^{3}\right)$ & 5,100 & 5,200 & 6,100 \\
\hline lymphocytes (\%) & 41.0 & 19.0 & 23.0 \\
\hline monocytes (\%) & 3.0 & 3.0 & 1.0 \\
\hline eosinophils (\%) & 1.0 & 3.0 & 1.0 \\
\hline neutrophils (\%) & 55.0 & 75.0 & 75.0 \\
\hline Hemoglobin $(\mathrm{g} / \mathrm{dl})$ & 15.6 & 15.9 & 14.8 \\
\hline Platelets $\left(/ \mathrm{mm}^{3}\right)$ & $14.3 \times 10^{4}$ & $17.0 \times 10^{4}$ & $17.3 \times 10^{4}$ \\
\hline $\mathrm{CRP}(\mathrm{mg} / \mathrm{dl})$ & $<0.2$ & 0.9 & 0.5 \\
\hline PT (sec) & $10.7(11.0)$ & $11.9(10.9)$ & $12.1(11.2)$ \\
\hline PTT (sec) & $22.4(23.3)$ & $25.3(25.8)$ & $26.5(28.6)$ \\
\hline LDH (IU) & 1,538 & 9.950 & $\underline{6,944}$ \\
\hline isozyme 1 & N.D. & N.D. & 301 \\
\hline 2 & N.D. & N.D. & 491 \\
\hline 3 & N.D. & N.D. & 298 \\
\hline 4 & N.D. & N.D. & 1,753 \\
\hline 5 & N.D. & N.D. & 4,101 \\
\hline AST (IU) & $\underline{2,555}$ & $\underline{8,000}$ & $\underline{6.110}$ \\
\hline ALT (IU) & 3.430 & 4,360 & 4,178 \\
\hline Total bilirubin (mg/dl) & $\underline{2.0}$ & $\underline{2.8}$ & 1.9 \\
\hline$\gamma$-GTP (IU) & 155 & 243 & 157 \\
\hline ALP (IU) & 288 & 263 & $\overline{261}$ \\
\hline CK (IU) & N.D. & 80 & 81 \\
\hline IgM HA antibody & $(-)$ & $(-)$ & $(-)$ \\
\hline HBs antigen & $(-)$ & $(-)$ & $(-)$ \\
\hline IgM HBc antibody & $(-)$ & $(-)$ & $(-)$ \\
\hline HCV antibody & N.D. & $(-)$ & $(-)$ \\
\hline HCV RNA (PCR method) & N.D. & N.D. & $(-)$ \\
\hline Anti-nuclear antibody & N.D. & $(-)$ & $(-)$ \\
\hline Anti-mitochondrial antibody & N.D. & $(-)$ & $(-)$ \\
\hline
\end{tabular}

N.D.: not done, CRP: C-reactive protein, PT: prothrombin time, PTT: partial thromboplastin time, LDH: lactate dehydrogenase, AST: aspartate aminotransferase, ALT: alanine aminotransferase, $\gamma$-GTP: $\gamma$-glutamyl transpeptidase, ALP: alkaline phosphatase, CK: creatine kinase, Ig: immunoglobulin, HA: hepatitis A, HBs: hepatisis B surface, HBc: hepatitis B core, HCV: hepatitis $C$ virus, RNA: ribonucleic acid, PCR: polymerase chain reaction.

Table 2. Allergy Examinations

\begin{tabular}{lrll}
\hline & \multicolumn{3}{c}{ May 29, 1993 } \\
\hline Total IgE (U/ml) & $\underline{407}$ & & \\
RAST (PRU/ml) & & & Prick skin tests \\
$\quad$ Wheat & $<0.35$ & Wheat & $(+)$ \\
Milk & $<0.35$ & Milk & $(-)$ \\
Barley & $<0.35$ & Rice & $(-)$ \\
Candida & $\underline{8.68}$ & Candida & $(+)$ \\
Aspergillus & $<0.35$ & Meat & $(-)$ \\
Alternaria & $<0.35$ & Shrimp & $(-)$ \\
House dust & $\underline{1.27}$ & Crab & $(-)$ \\
Dermatophagoides & $<0.35$ & & \\
\hline
\end{tabular}

Ig: immunoglobulin, RAST: radioallergosorbent test. caria, air way obstruction and hypotension.

We suspected wheat allergy in the present case because the intake of wheat-containing foods was common in three episodes. However, wheat containing foods did not necessarily induce the attacks, suggesting that they were not caused by simple wheat allergy and that other additional factors might be present to induce anaphylaxis. His episodes characteristically occurred after exercise, suggesting that his illness was FDEIAn. The etiology of acute liver injury in this case was not viral (type A, B, C) nor drug induced. An etiological relationship with FDEIAn was suspected, because acute liver injury developed during FDEIAn. In relation to this, ischemic hepatitis was thought to be a possible etiology.

Ischemic hepatitis is a clinical entity which simulates acute hepatitis and is produced by hypoxic hepatocellular necrosis 
secondary to acute circulatory failure $(8,9)$. The histology is characterized by centrilobular hepatocyte necrosis without inflammation (8). Laboratory results are characterized by a marked and rapid elevation of serum aminotransferase activity levels, especially AST (9). The values rapidly return to normal, with recovery in less than one week. The generally accepted causes of ischemic hepatitis are congestive heart failure $(10,11)$ with or without shock, long-lasting shock without heart failure (trauma, dehydration, hemorrhage, burns, sepsis), heatstroke and rare cases of severe hypoxemia $(9,10,12-15)$. The prognosis is usually determined by the initial cause. Hepatic blood flow diminishes parallel to the decrease in cardiac output, the liver receives a fairly constant $25 \%$ of cardiac output, but it compensates for the decrease in blood flow by increasing the amount of oxygen extracted from the blood (16). If the hepatic blood flow drops below a critical level, this compensatory mechanism becomes inadequate, causing hypoxic injury. The clinical data of the present case were consistent with the characteristics of ischemic hepatitis in that the serum aminotransferase levels were rapidly elevated to more than 1,000 IU and quickly returned to normal values (Fig. 3), whereas the histological finding of the liver biopsy was not consistent (Fig. 2). It may be because liver biopsy was performed when the serum aminotransferase values were not at peak but were almost normal. Indeed, when clinical and laboratory features are typical and when other causes of acute hepatitis are excluded, liver biopsy is not mandatory for the diagnosis $(8,9,17)$. However, ischemic hepatitis remains a rare event in patients with anaphylaxic shock, despite the high frequency of shock.

In addition, it is well known that congestion in the liver and an increase of the portal pressure occur in animals (18) and in humans (19) during anaphylactic shock. However, the exact mechanism responsible for anaphylactic hepatic congestion and portal hypertension remains obscure, although various chemical mediators of anaphylaxis have been shown to increase the portal pressure (20-24). Recently Yamaguchi et al proposed that an increase in sinusoidal pressure caused by hepatic venoconstriction may play an important role in the development of portal hypertension and hepatic congestion associated with anaphylactic shock (25). But anaphylactic shock including FDEIAn rarely induces liver injury:

In our case alcohol intake may have caused acute liver injury, but alcohol intake of this amount alone could not cause acute liver injury. We speculated that the interaction of anaphylactic shock and alcohol might have induced the liver injury. There are many theories about the mechanisms of alcoholic liver injury. The underlying causes of alcohol-induced liver damage are more elusive. Studies have demonstrated toxicity of alcohol and metabolites to a wide variety of intracellular processes (26). But co-factors, immune, genetic or environmental, are necessary to explain the varying clinical manifestations of alcohol-induced tissue injury. Oshita et al reported that acute ethanol intake induced vasoconstriction of the liver which caused focal hepatocellular injury in rats (27). In addition, Bauer et al suggested that chronic ethanol intake exacer- bates microvascular and hepatocellular injury after shock, probably involving increased sinusoidal contractile responsiveness (28). Therefore, in the present case, ethanol may have enhanced the liver damage in addition to hepatic injury produced by anaphylactic shock.

To prevent FDEIAn, prophylactic use of anti-histamine has been reported (29). We recommended that the patient does not to do exercise for three hours after eating wheat-containing foods and subsequently, there has been no sign of FDEIAn for the last six years.

\section{References}

1) Sheffer AL, Austen KF. Exercise-induced anaphylaxis. J Allergy Clin Immunol 66: 106-111, 1980.

2) Nichols AW. Exercise-induced anaphylaxis and urticaria. Clin Sports Med 11: 303-312, 1992.

3) Dohi M, Suko M, Sugiyama H, et al. Food-dependent, exercise-induced anaphylaxis: A study on 11 Japanese cases. J Allergy Clin Immunol 87: 34-40, 1991.

4) Maulitz RM, Pratt DM, Schocket AL. Exercise-induced anaphylactic reaction to shellfish. J Allergy Clin Immunol 63: 433-434, 1979.

5) Sheffer AL, Tong AK, Murphy GF, Lewis RA, McFadden ER Jr, Austen KF. Exercise-induced anaphylaxis: A serious form of physical allergy associated with mast cell degranulation. J Allergy Clin Immunol 75: 479484, 1985.

6) Kaplan AP. Urticaria and angioedema. in: Allergy, Principles and Practice. 3rd ed. E Middleton Jr, CE Reed, Eds. CV Mosby, St. Louis, 1988: 1377-1401.

7) Ordoqui E, Zubeldia JM, Aranzabal A, et al. Serum tryptase levels in adverse drug reactions. Allergy 52: 1102-1105, 1997.

8) Gibson PR, Dudley FJ. Ischemic hepatitis: clinical features, diagnosis and prognosis. Aust NZ J Med 14: 822-825, 1984.

9) Gitlin N, Serio KM. Ischemic hepatitis: widening horizons. Am J Gastroenterol 87: 831-836, 1992.

10) Bynum TE, Boitnott JK, Maddrey WC. Ischemic hepatitis. Dig Dis Sci 24: 129-135, 1979.

11) Cohen JA, Kaplan MM. Left-sided heart failure presenting as hepatitis. Gastroenterology 74: 583-587, 1978.

12) Vescia FG, Peck OC. Liver disease from heatstroke. Gastroenterology 43: 340-343, 1962.

13) Kew M, Bersohn I, Seftel H, Kent G. Liver damage in heatstroke. Am J Med 49: 192-202, 1970.

14) Bianchi L, Ohnacker H, Beck K, Zimmerli-Ning M. Liver damage in heatstroke and its regression: A biopsy study. Hum Pathol 3: 237-248, 1972.

15) Birgens HS, Henriksen J, Matzen P, Poulsen H. The shock liver. Clinical and biochemical findings in patients with centrilobular liver necrosis following cardiogenic shock. Acta Med Scand 204: 417-421, 1978.

16) Richardson PDI, Withrington PG. Liver blood flow I. Intrinsic and nervous control of liver blood flow. Gastroenterology 81: 159-173, 1981.

17) Hickman PE, Potter JM. Mortality associated with ischaemic hepatitis. Aust NZ J Med 20: 32-34, 1990.

18) Weil R. Studies in anaphylaxis. XXI Anaphylaxis in dogs. A study of the liver in shock and in peptone poisoning. J Immunol 2: 525-556, 1917.

19) James LP, Austen KF. Fatal systemic anaphylaxis in man. N Engl J Med 270: 597-603, 1964.

20) Honer Andrews WH, Hecker R, Maegraith BG, Ritchie HD. The action of adrenaline, L-noradrenaline, acetylcholine and other substances on the blood vessels of the perfused canine liver. J Physiol 128: 413-434, 1955.

21) Bennett TD, MacAnespie CL, Rothe CF. Active hepatic capacitance responses to neural and humoral stimuli in dogs. Am J Physiol 242 (Heart Circ Physiol 11): H1000-1009, 1982.

22) Bennett TD, Rothe CF. Hepatic capacitance responses to changes in flow 


\section{OKANO et al}

and hepatic venous pressure in dogs. Am J Physiol 240 (Heart Circ Physiol 9): H18-28, 1981.

23) Greenway CV, Oshiro G. Effects of histamine on hepatic volume (outflow block) in anaesthetized dogs. Br J Pharmacol 47: 282-290, 1973.

24) Richardson PDI, Withrington PG. Responses of the simultaneously-perfused hepatic arterial and portal venous vascular beds of the dog to histamine and 5-hydroxytryptamine. Br J Pharmacol 64: 581-588, 1978.

25) Yamaguchi Y, Shibamoto T, Hayashi T, Saeki Y, Tanaka S. Hepatic vascular response to anaphylaxis in isolated canine liver. Am J Physiol 267 (1 Pt 2): R268-274, 1994.

26) Lieber CS. Biochemical factors in alcoholic liver disease. Semin Liver
Dis 13: 136-153, 1993.

27) Oshita M, Sato N, Yoshihara H, et al. Ethanol-induced vasoconstriction causes focal hepatocellular injury in the isolated perfused rat liver. Hepatology 16: 1007-1013, 1992.

28) Bauer I, Bauer M, Pannen BHJ, Leinwand MJ, Zhang JX, Clemens MG. Chronic ethanol consumption exacerbates liver injury following hemorrhagic shock: role of sinusoidal perfusion failure. Shock 4: 324-331, 1995.

29) Fujimoto S, Kurihara N, Hirata K, Kamimori T, Tanaka S, Takeda T. Successful prophylaxis of wheat-dependent exercise-induced anaphylaxis with terfenadine. Intern Med 34: 654-656, 1995. 